\title{
Risk Factors for Recurrent Shoulder Instability after Arthroscopic Revision Anterior Stabilization
}

Favian Su, BS, Marcin Kowalczuk, MD, Stephenson Amanze Ikpe, MD, Hannah Lee, MD, PhD, Soheil Sabzevari, MD, Albert Lin, MD

University of Pittsburgh Medical Center, Pittsburgh, PA, USA.

Objectives: Individuals that fail arthroscopic anterior stabilization of the shoulder represent a unique and challenging patient population. To date, there have been few large studies that have investigated failure rates following arthroscopic revision anterior stabilization (ARAS) for failed primary arthroscopic stabilization. This study aims to determine the risk factors for recurrence of shoulder instability following ARAS. We hypothesized that male gender, younger age, participation in contact sports, significant glenoid and/or humeral bone loss, ligamentous laxity, and worker's compensation would increase the risk of revision failure.

Methods: Patients who underwent ARAS after a failed arthroscopic primary Bankart repair and had a minimum of 2-year follow-up were included in this study. Glenoid and humeral bone loss were quantitatively assessed using pre-operative T1-weighted magnetic resonance arthrograms to determine if the lesions were on- or off-track. Failure was defined as a recurrent dislocation or subluxation. Chi-square test and t-test were used to compare demographical and surgical parameters between failure and non-failure groups. The significance level was set to 0.05 .

Results: Sixty-five patients [age at revision $=26$ years (range, $15-57), 44(68 \%)$ male] met the inclusion criteria. The mean follow-up time was 4.7 years (range, $2-10.8)$. Twenty-seven patients $(42 \%)$ had a failed revision at a mean time of 2.3 years (range, $0.2-6.1$ ). Age less than 22 years old, ligamentous laxity, the presence of an offtrack lesion, and a concomitant superior labral anterior to posterior were significantly associated with revision failure $(p<0.05)$ (Table 1). No difference was observed in the size of glenoid defect between failure and non-failure groups $(14.1 \% \pm 4.4 \%$ vs. $13.7 \% \pm 3.9 \%, p=0.762)$. The width and depth of the Hill-Sachs lesions were not significantly different between groups (width: $15.3 \pm 5.1 \mathrm{~mm}$ vs. $14.2 \pm 4.8 \mathrm{~mm}, \mathrm{p}=0.432$; depth: $4.2 \pm 2.3 \mathrm{~mm}$ vs. $3.5 \pm 1.8 \mathrm{~mm}$, $p=0.244)$. On multivariate analysis, only the presence of an off-track lesion, age less than 22 years, and ligamentous laxity were independent predictors for recurrent instability $(O R=8.9, p=0.022 ; O R=5.4, p=0.028$; $\mathrm{OR}=7.8, \mathrm{p}=0.031$, respectively).

Conclusion: The failure rate of arthroscopic revision anterior stabilization was $42 \%$ with off-track lesions, age less than 22 years, and ligamentous laxity independent risk factors for recurrent instability. While ARAS may be a viable treatment option in the appropriate setting, our study suggests that considerable thought should be exercised before utilizing this approach given the significant number of patients who suffered recurrent instability at greater than 2years follow-up. For young patients with off-track lesions and/or evidence of ligamentous laxity on physical exam, strong consideration should be given to either an open Bankart repair, a bony augmentation procedure such as a Bristow-Latarjet procedure, or an arthroscopic revision approach with additional augmentation such as a remplissage.

This open-access article is published and distributed under the Creative Commons Attribution - NonCommercial - No Derivatives License (http://creativecommons.org/licenses/by-nc-nd/4.0/), which permits the noncommercial use, distribution, and reproduction of the article in any medium, provided the original author and source are credited. You may not alter, transform, or build upon this article without the permission of the Author(s). For article reuse guidelines, please visit SAGE's website at http://www.sagepub.com/journals-permissions. 


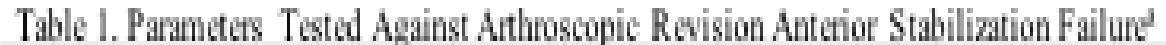

\begin{tabular}{|c|c|c|c|c|}
\hline Parametat & Rwision Fialux & $\begin{array}{c}\text { No Revision } \\
\text { Faillumb }\end{array}$ & OR & pryalue \\
\hline Age at Revision $<22 y$ & $16 / 27(59 \%)$ & $13 / 38(34 \%)$ & 2.80 & 0.045 \\
\hline Ligamentous Laxity & $10 / 27(37 \%)$ & $5 / 8(13 \%)$ & 388 & 0.0124 \\
\hline Off-Tratk Lesion & $1022(45 \%)$ & $436(11 \%)$ & 6.67 & 0.003 \\
\hline \$LAPTear & $11 / 27(41 \%)$ & $6188(16 \%)$ & 3.67 & 0.024 \\
\hline Male Gituder & $17 / 27(69 \%)$ & $27 / 38(71 \%$ & 0.69 & 0.492 \\
\hline $\mathrm{BMI}>30 \mathrm{~kg} \mathrm{~m}^{2}$ & $3 / 24(13 \%)$ & $3 / 27(11 \%)$ & 1.14 & 1.000 \\
\hline Domithant Side lnijund & $20 / 27(74 \%)$ & $23 / 38(61 \%)$ & 1.86 & 0.255 \\
\hline Bilatual Antutor Instability & $3 / 27(11 \%)$ & $7 / 38(18 \%)$ & 0.55 & 0.503 \\
\hline Workcts' Compinsation & $3 / 27(11 \%)$ & $9 / 38(24 \%)$ & 0.40 & 0.331 \\
\hline Atblites & $12 / 27(44 \%)$ & $17 / 38(45 \%)$ & 0.99 & 0.981 \\
\hline Contact Sports & $9 / 2(75 \%)$ & $12 / 1701 \%$ & 1.25 & 1.000 \\
\hline Competitive Lavd & $312(25 \%)$ & $317(18 \%)$ & 1.56 & 0.669 \\
\hline Opun P'nimary Bankart Repail' & $2 / 23(9 \%)$ & $435(11 \%)$ & 0.74 & 1.000 \\
\hline Traumatie Rquair Failun & $71809 \%$ & $1635(46 \%)$ & 0.76 & 0.695 \\
\hline Time fon Failue to Ravision 1 y & $21 / 27(78 \%)$ & $31 / 38(82 \%)$ & 0.79 & 0.706 \\
\hline Total Numbet of Anchors 33 & $6 / 2000 \%$ & $100003 \%$ & 0.86 & 0.804 \\
\hline 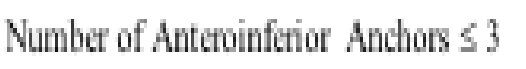 & $1420(707)$ & $19 / 30(63 \%)$ & 1.35 & 0.626 \\
\hline Labual Thar $>120^{\circ}$ & $13 / 20165 \%$ & $203067 \%$ & 0.93 & 0.903 \\
\hline
\end{tabular}

"Data expessed as counthumber of avillable wase (\%). Competitive lewet is defind as oollegiate of

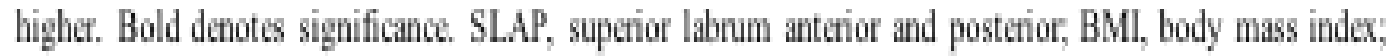
OR, odds ratio. 